\title{
Boron and Nitrogen in GaAs and InP Melts Equilibrated with $\mathrm{B}_{2} \mathrm{O}_{3}$ Flux
}

\author{
Tsuyoshi Yamada ${ }^{1}$, Taku Kudo*1, Kazuki Tajima*2, ${ }^{*}$ Akira Otsuka $^{2}$, \\ Takayuki Narushima ${ }^{3}$, Chiaki Ouchi ${ }^{3}$ and Yasutaka Iguchi ${ }^{3}$ \\ ${ }^{1}$ Compound Semiconductor Wafer Dept., Dowa Semiconductor Co., Ltd, Akita 011-0911, Japan \\ ${ }^{2}$ Semiconductor Business Unit, Dowa Mining Co., Ltd., Tokyo 100-8282, Japan \\ ${ }^{3}$ Department of Metallurgy, Tohoku University, Sendai 980-8579, Japan
}

\begin{abstract}
The boron and nitrogen contents of GaAs and InP melts equilibrated with $\mathrm{B}_{2} \mathrm{O}_{3}$ flux were examined at 1523 and $1373 \mathrm{~K}$, respectively, using a chemical equilibrium technique. GaAs or InP was melted with $\mathrm{B}_{2} \mathrm{O}_{3}$ flux in a silica ampoule with and without a BN crucible. The boron content decreased with increasing nitrogen content in both of the melts equilibrated with $\mathrm{B}_{2} \mathrm{O}_{3}$ flux and $\mathrm{BN}$. The solubility product of $\mathrm{BN}$ in the melts was expressed as a function of nitrogen content. The relationship between the boron and nitrogen contents of a GaAs melt coexisted with BN agreed well with that in the residue after LEC crystal growth of GaAs. The boron content of the GaAs melt coexisted with silica was much larger than that of the GaAs melt with $\mathrm{BN}$. It was suggested that the reduction of $\mathrm{B}_{2} \mathrm{O}_{3}$ by silicon introduced into the melt from silica led the increase of boron content.
\end{abstract}

(Received December 17, 2003; Accepted February 17, 2004)

Keywords: liquid-encapsulated Czochralski method, GaAs, InP, $\mathrm{B}_{2} \mathrm{O}_{3}$, nitrogen, boron

\section{Introduction}

III-V compound semiconductors such as GaAs and InP are used to high-speed and high-frequency devices and optical devices because of their excellent electrical and optical properties. Large-diameter single crystals of GaAs and InP are mainly produced by the liquid-encapsulated Czochralski (LEC) and the vertical gradient freeze (VGF) methods. ${ }^{1)}$ In both of the processes, the melt of GaAs or InP coexists with $\mathrm{B}_{2} \mathrm{O}_{3}$ flux as a liquid encapsulant and is in contact with a crucible made of $\mathrm{BN}$ or silica at high temperature and high pressure. Impurities such as boron, carbon, nitrogen or oxygen can be introduced from the $\mathrm{B}_{2} \mathrm{O}_{3}$ flux and the crucible into the III-V melt, and incorporated into the single crystal during the growth process. ${ }^{2-4)}$ Therefore, the reactions between a III-V melt and $\mathrm{B}_{2} \mathrm{O}_{3}$ flux or crucible are important factors governing the content and distribution of impurities in III-V single crystals. Boron and carbon are important residual impurities in undoped GaAs single crystals grown by the LEC and VGF methods. ${ }^{5)}$ Carbon has been shown to be the dominant residual acceptor impurity which affects the characteristics of undoped semi-insulating crystals. ${ }^{2,6)}$ Effects of boron on electrical properties have also been reported. ${ }^{7)}$ It is known that boron and carbon contents can be decreased by decreasing the water content of the $\mathrm{B}_{2} \mathrm{O}_{3}$ flux ${ }^{3,8,9)}$ or increasing the strength of the magnetic field. ${ }^{10)}$ These methods, however, cannot control the carbon and boron contents independently.

Recent reports have noted that adjustment of ambient gas partial pressures in a crystal growth chamber can independently control the contents of boron and carbon in III-V crystals. ${ }^{11-15)}$ Increasing the ambient $\mathrm{N}_{2}$ gas pressure in the crystal growth chamber increases the nitrogen content in a III-V melt according to eq. (1).

\footnotetext{
${ }^{* 1}$ Graduate Student, Tohoku University.

${ }^{* 2}$ Graduate Student, Tohoku University, Present address: Synergy Materials Research Center, AIST, Nagoya 463-8560, Japan.
}

$$
\frac{1}{2} \mathrm{~N}_{2}(\mathrm{~g})=\underline{\mathrm{N}}(\text { in III-V melt })
$$

When $\mathrm{BN}$ is used as a crucible material, eq. (2) suggests that the boron content of a III-V melt decreases with increasing pressure of ambient $\mathrm{N}_{2}$ gas.

$$
\underline{\mathrm{B}}(\text { in III-V melt })+\frac{1}{2} \mathrm{~N}_{2}(\mathrm{~g})=\mathrm{BN}(\mathrm{s})
$$

Therefore, thermodynamic study of boron and nitrogen in III$\mathrm{V}$ melts is needed in order to control the transport of impurities during the crystal growth. Although Korb et al. calculated the contents of boron and nitrogen in a GaAs melt, ${ }^{14)}$ there are no experimental reports on the relationship between the boron and nitrogen contents of III-V melts.

In the present work, the boron and nitrogen contents of GaAs and InP melts equilibrated with $\mathrm{B}_{2} \mathrm{O}_{3}$ flux in a $\mathrm{BN}$ crucible were measured at 1523 and $1373 \mathrm{~K}$, respectively, and are discussed from a thermodynamic standpoint. The boron and nitrogen contents of the GaAs melt are compared with those in the residue after the industrial LEC crystal growth process.

\section{Experimental}

A silica ampoule $\left(17^{\mathrm{OD}} \times 13^{\mathrm{ID}} \times 100^{\mathrm{H}}\right)$ made of highly pure quartz glass tube (T2030, Toshiba Ceramics Co., Ltd.) was employed for the melting of GaAs (99.999\%) or InP $(99.999 \%)$ and $\mathrm{B}_{2} \mathrm{O}_{3}$ flux in a $\mathrm{BN}$ crucible $\left(12^{\mathrm{OD}} \times 10^{\mathrm{ID}} \times\right.$ $30^{\mathrm{H}}, \mathrm{N}-1$, Denka) as shown in Fig. 1(a). Figure 1(b) shows the schematic cross section of the Ga-As alloy and $\mathrm{B}_{2} \mathrm{O}_{3}$ flux, which were directly melted in a silica ampoule. ${ }^{16)}$ The As content of the Ga-As alloy varied from 0 to 50 at $\%$. Before the equilibrium experiment in a silica ampoule, $\mathrm{B}_{2} \mathrm{O}_{3}$ flux was prepared by melting $\mathrm{B}_{2} \mathrm{O}_{3}$ with an $\mathrm{H}_{2} \mathrm{O}$ content of less than 103 mass ppm and $\mathrm{Ga}_{2} \mathrm{O}_{3}$ or $\mathrm{In}_{2} \mathrm{O}_{3}$ in a platinum crucible. $\mathrm{B}_{2} \mathrm{O}_{3}$ fluxes saturated with $\mathrm{Ga}_{2} \mathrm{O}_{3}$ and $\mathrm{In}_{2} \mathrm{O}_{3}$ were used in the melting of GaAs and InP, respectively. The solubility of $\mathrm{Ga}_{2} \mathrm{O}_{3}$ or $\mathrm{In}_{2} \mathrm{O}_{3}$ in $\mathrm{B}_{2} \mathrm{O}_{3}$ flux and the solid phase 
(a) Stoichiometric GaAs or InP melt
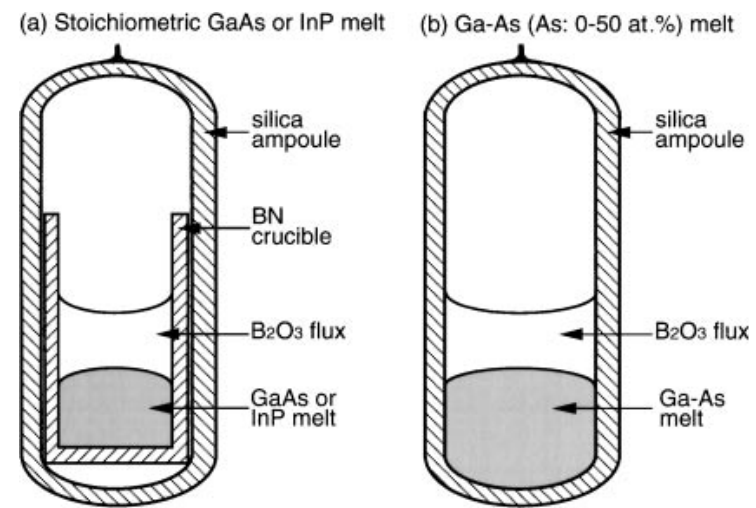

Fig. 1 Schematic cross sections of (a) stoichiometric GaAs or InP melt equilibrated with $\mathrm{B}_{2} \mathrm{O}_{3}$ flux and $\mathrm{BN}$ and (b) Ga-As melt (As: 0-50 at\%) equilibrated with $\mathrm{B}_{2} \mathrm{O}_{3}$ flux and $\mathrm{SiO}_{2}$.

equilibrated with $\mathrm{B}_{2} \mathrm{O}_{3}$ flux have been reported elsewhere by the present authors. ${ }^{17)}$ It was confirmed that the content of $\mathrm{Ga}_{2} \mathrm{O}_{3}$ or $\mathrm{In}_{2} \mathrm{O}_{3}$ in the flux was at the solubility limit at each equilibrium temperature.

A silica ampoule with GaAs or InP (small pieces, $3 \mathrm{~g}$ ) and $\mathrm{B}_{2} \mathrm{O}_{3}$ flux (small pieces, $0.5 \mathrm{~g}$ ), which was evacuated to vacuum $(<1 \mathrm{~Pa})$ and sealed at room temperature, was heated in an alumina reaction tube using an electrical resistance furnace and held at 1523 or $1373 \mathrm{~K}$. The holding time was $86.4 \mathrm{ks}$, which was sufficient time for boron and nitrogen to attain equilibrium in the III-V melt coexisted with the $\mathrm{B}_{2} \mathrm{O}_{3}$ flux and $\mathrm{BN}$ or silica. After establishing equilibrium, the III$\mathrm{V}$ melt and $\mathrm{B}_{2} \mathrm{O}_{3}$ flux in a silica ampoule was quenched with liquid nitrogen, followed by chemical analysis.

The boron, nitrogen and silicon contents of the quenched III-V specimen were analyzed quantitatively. The boron and silicon contents were determined by inductively coupled plasma (ICP) atomic emission spectroscopy (ICPS8100, Shimadzu). The glow discharge plasma mass spectroscopy (GDMS) method (VG9000, VG) ${ }^{18)}$ was employed for nitrogen analysis, because the nitrogen content of the III-V melt was less than 10 mass ppm. The GDMS merits attention as an analysis method for a trace element in a solid sample. The system is used for the quantitative analysis of high-purity materials including the determination of dopants and impurities at ultratrace levels in semiconductors. The stable and low electrical power discharge minimizes matrix effects and generates fewer multivalent ions than SSMS (spark source mass spectrometry) in the sputtering and ionization process. A double focus mass spectrometer, which provides a means of performing trace determinations at very low levels, was used for mass spectrometry. The relative sensitivity factor (RSF) is needed to quantify the nitrogen content from the ion intensity. The value of the RSF of nitrogen in GaAs has not been reported. It is known that the value of the RSF is related to the first ionization potential. ${ }^{19,20)}$ The value of the RSF of oxygen in GaAs has been reported to be $13 .{ }^{21)}$ Since the first ionization potential of nitrogen is comparable to that of oxygen, 10 was used for the RSF of nitrogen in the present work. The in-depth profile of nitrogen in a GaAs single crystal was measured to examine the influence of nitrogen adsorbed on the surface of specimens physically and chemically. A constant value was obtained for the nitrogen content

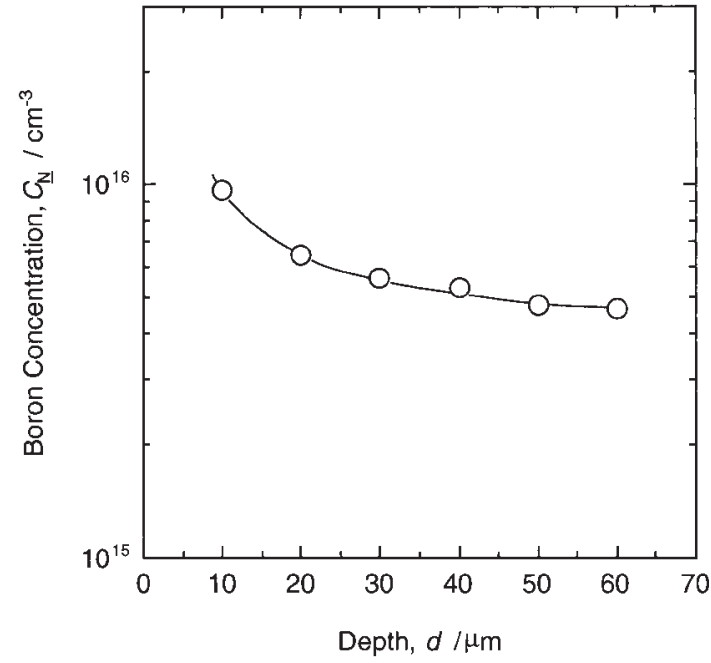

Fig. 2 Depth profile of nitrogen concentration in single crystal GaAs measured by GDMS.

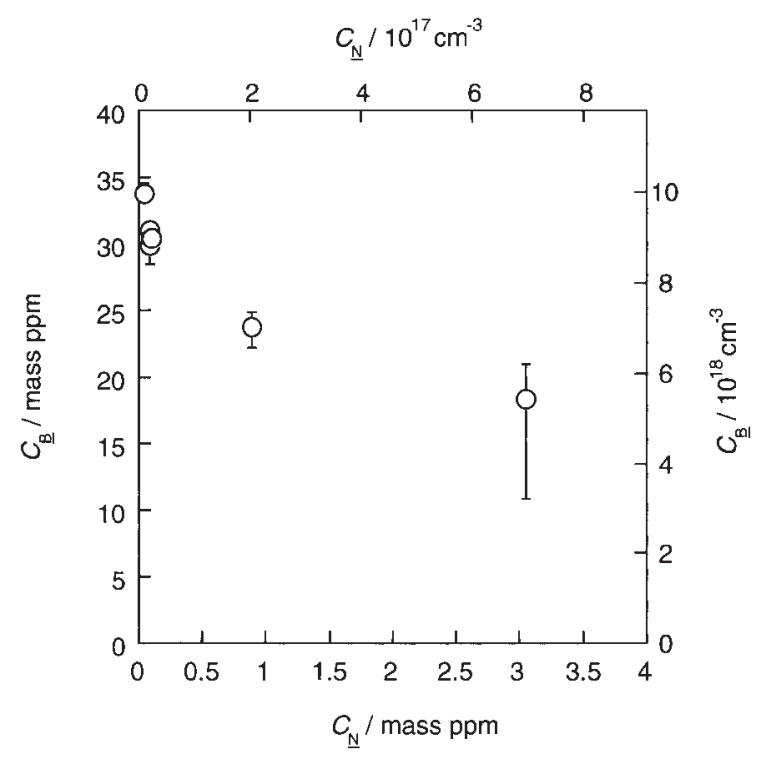

Fig. 3 Relationship between boron and nitrogen contents of a GaAs melt equilibrated with $\mathrm{B}_{2} \mathrm{O}_{3}$ flux and $\mathrm{BN}$ crucible at $1523 \mathrm{~K}$.

after sputtering $60 \mu \mathrm{m}$ from the surface of GaAs as shown in Fig. 2. Therefore, the ion intensity at a depth of $60 \mu \mathrm{m}$ was used to calculate the nitrogen content of GaAs.

\section{Results and Discussion}

\subsection{Boron and nitrogen contents of a III-V melt}

Figures 3 and 4 show the relationship between the boron and nitrogen contents of GaAs and InP melts equilibrated with $\mathrm{B}_{2} \mathrm{O}_{3}$ flux at 1523 and $1373 \mathrm{~K}$, respectively. The melt was coexisted with $\mathrm{BN}$. The boron content increased with decreasing nitrogen content in both the GaAs and InP melts. The equilibrium reaction between boron and nitrogen in a III$\mathrm{V}$ melt coexisted with $\mathrm{BN}$ can be expressed by eq. (3).

$$
\begin{aligned}
& \underline{\mathrm{B}}(1 \mathrm{mass} \% \text { in III-V melt }) \\
& \quad+\underline{\mathrm{N}}(1 \text { mass } \% \text { in III-V melt })=\mathrm{BN}(\mathrm{s})
\end{aligned}
$$




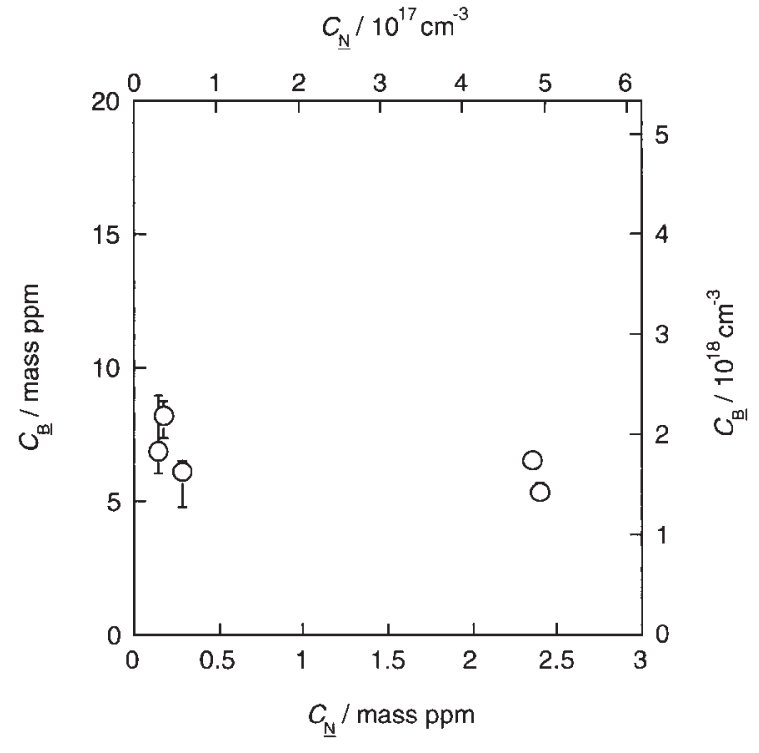

Fig. 4 Relationship between boron and nitrogen contents of an InP melt equilibrated with $\mathrm{B}_{2} \mathrm{O}_{3}$ flux and $\mathrm{BN}$ at $1373 \mathrm{~K}$.

Since the purity of the BN crucible used in the present work was greater than $99 \%$, the activity of BN can be set to unity referred to pure solid BN. Then, the equilibrium constant of eq. (3) can be written as eq. (4).

$$
\begin{aligned}
K_{(3)} & =\frac{1}{a_{\underline{\mathrm{B}}} \cdot a_{\underline{\mathrm{N}}}} \\
& =\frac{1}{f_{\underline{\mathrm{B}}}\left[C_{\underline{\mathrm{B}}} / \operatorname{mass} \%\right] \cdot f_{\underline{\mathrm{N}}}\left[C_{\underline{\mathrm{N}}} / \operatorname{mass} \%\right]}
\end{aligned}
$$

where $a_{i}$ is the Henrian activity of species $i$ (= boron or nitrogen) and its standard state in a III-V melt is taken as 1 mass $\%$, and $f_{i}$ is the Henrian activity coefficient of species $i$ in III-V melt. Equation (4) gives eq. (5).

$$
\begin{aligned}
\log \left[C_{\underline{\mathrm{B}}} / \operatorname{mass} \%\right]= & -\log \left[C_{\underline{\mathrm{N}}} / \operatorname{mass} \%\right] \\
& -\left\{\log K_{(3)}+\log \left(f_{\underline{\mathrm{B}}} \cdot f_{\underline{\mathrm{N}}}\right)\right\}
\end{aligned}
$$

Figure 5 shows the relationship between the boron and nitrogen contents of GaAs and InP melts coexisted with BN. If there is no interaction between solutes in the III-N melt, i.e., $\log f_{\underline{\mathrm{B}}} \approx 0$ and $\log f_{\underline{\mathrm{N}}} \approx 0$, the slope of the line shown in Fig. 5 is expected to be -1 from eq. (5). Since the slopes of the lines in Fig. 5 are -0.14 and -0.07 for GaAs and InP melts, respectively, the interaction between solutes in the III$\mathrm{V}$ melt appears to be strong.

Figure 6 shows the solubility product of BN in a III-V melt $\left(K_{(3)}^{\prime}=\left[C_{\mathrm{B}} / \mathrm{mass} \%\right] \cdot\left[C_{\mathrm{N}} / \mathrm{mass} \%\right]\right)$ as a function of nitrogen content $\left(C_{\underline{N}}\right)$. Equations (6) and (7) can be obtained by assuming a linear relationship between $\log K_{(3)}^{\prime}$ and $\log \left[C_{\underline{N}} / \operatorname{mass} \%\right]$.

$$
\begin{aligned}
& \log K_{(3) \text { in GaAs }}^{\prime}= 0.863 \log \left[C_{\underline{N}} / \text { mass\% }\right]-3.21 \\
& \quad\left(1523 \mathrm{~K}, \log \left[C_{\underline{N}} / \text { mass } \%\right]:-5.3 \sim-3.5\right) \\
& \log K_{(3) \text { in InP }}^{\prime}=0.927 \log \left[C_{\underline{N}} / \text { mass } \%\right]-3.50 \\
& \quad\left(1373 \mathrm{~K}, \log \left[C_{\underline{N}} / \text { mass } \%\right]:-5.0 \sim-3.6\right)
\end{aligned}
$$

The boron content of the melt of Ga-As binary alloy with a range of As content up to 50 at $\%$ equilibrated with $\mathrm{B}_{2} \mathrm{O}_{3}$ flux

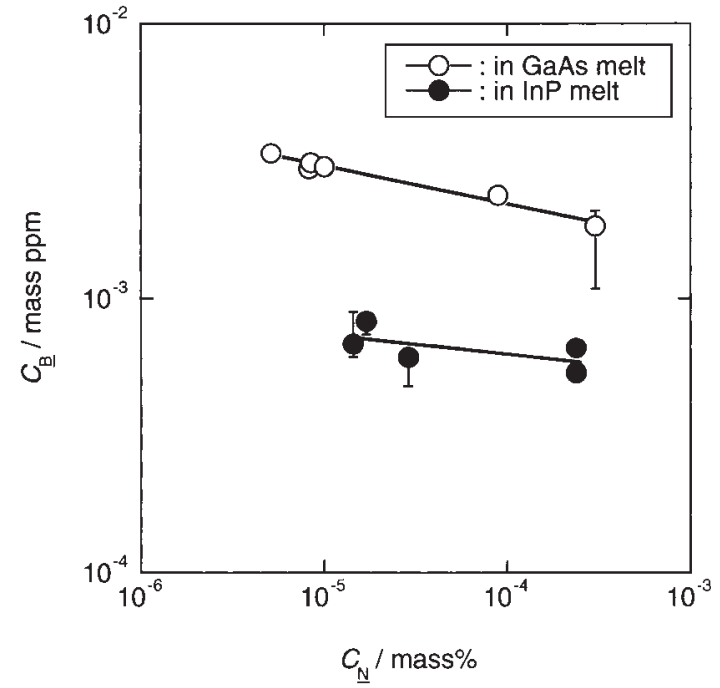

Fig. 5 Log-log plots of the relationship between boron and nitrogen content of GaAs and InP melts equilibrated with $\mathrm{B}_{2} \mathrm{O}_{3}$ flux and $\mathrm{BN}$ at $1523 \mathrm{~K}$ and $1373 \mathrm{~K}$, respectively.

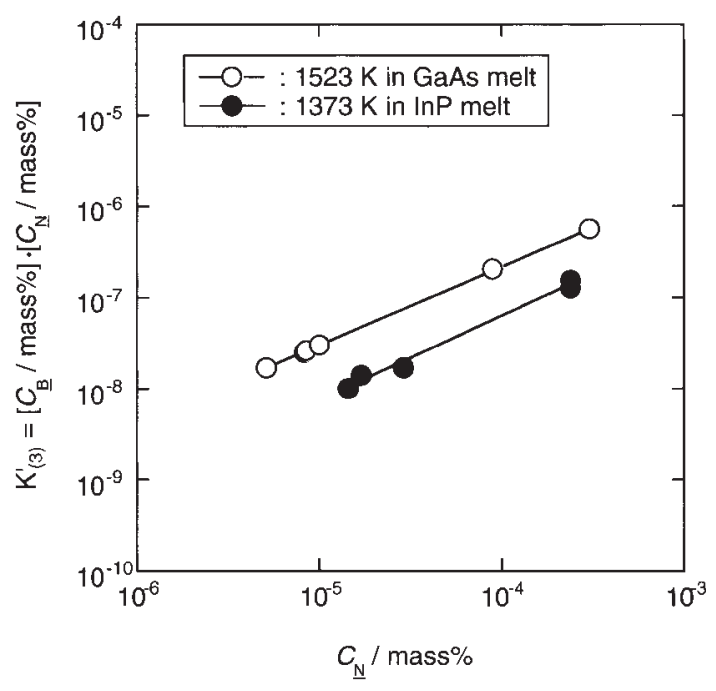

Fig. 6 Solubility products of boron and nitrogen in GaAs and InP melts equilibrated with $\mathrm{B}_{2} \mathrm{O}_{3}$ flux and $\mathrm{BN}$ at $1523 \mathrm{~K}$ and $1373 \mathrm{~K}$, respectively.

and silica is shown in Fig. 7. The boron content ranged between 300 and 500 mass ppm, which is much higher than that in the GaAs melt coexisted with BN (see Fig. 3). As mentioned in section 3.2 , the amount of silicon introduced into the melt of Ga-As alloy from silica is related to the increase of the boron content.

\subsection{Comparison with reported values of boron and nitrogen contents of III-V melts}

Although the boron and nitrogen contents of a III-V melt have not been measured experimentally, there are many experimental reports of the boron contents of single crystal GaAs, which is of commercial significance..$^{3,7,8,10,12,22-30)}$ The maximum content of boron in undoped GaAs single crystal grown by the LEC or VGF method ranged from $1 \times$ $10^{17} \mathrm{~cm}^{-3} \quad\left(0.34\right.$ mass ppm) to $1 \times 10^{18} \mathrm{~cm}^{-3} \quad(3.4$ mass ppm)..$^{3,8,10,12,22)}$ It has been reported that the addition of 


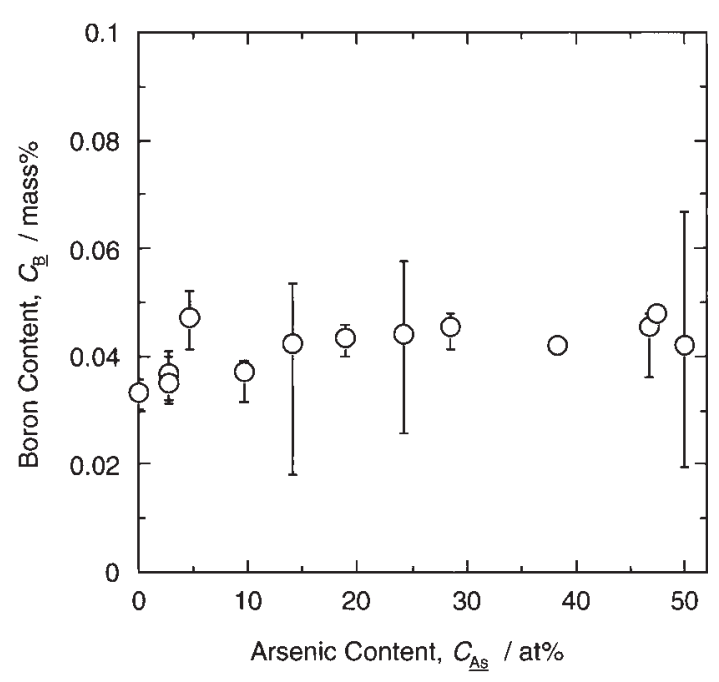

Fig. 7 Boron content of the melt of Ga-As alloy equilibrated with $\mathrm{SiO}_{2}$ and $\mathrm{B}_{2} \mathrm{O}_{3}$ flux at $1523 \mathrm{~K}$.

silicon to a GaAs melt increased the maximum content of boron in the resulting GaAs single crystals. Boron contents ranging from $5 \times 10^{17} \mathrm{~cm}^{-3}\left(1.7\right.$ mass ppm) to $1.9 \times 10^{19}$ $\mathrm{cm}^{-3}$ (64 mass ppm) have been reported for Si-doped GaAs single crystal. ${ }^{23,26-30)}$ The mechanism of boron incorporation can be explained by the following reaction: ${ }^{29,30)}$

$$
\begin{aligned}
& 3 \underline{\mathrm{Si}} \text { (in } \mathrm{GaAs} \text { melt })+2 \mathrm{~B}_{2} \mathrm{O}_{3}(l \text { in flux }) \\
& \quad=3 \mathrm{SiO}_{2}(l \text { in flux })+4 \underline{\mathrm{B}}(\text { in GaAs melt })
\end{aligned}
$$

That is, the reduction of $\mathrm{B}_{2} \mathrm{O}_{3}$ by silicon increases the boron content of the GaAs melt, and then boron in the melt is incorporated in the GaAs single crystal during growth. Boron content of less than $10^{16} \mathrm{~cm}^{-3}$ in Si-doped GaAs single crystal grown by the horizontal Bridgman method has been reported. ${ }^{27,28)}$ This suggests that the presence of $\mathrm{B}_{2} \mathrm{O}_{3}$ flux is essential for the increase of boron content in Si-doped GaAs single crystals, and confirms the validity of the mechanism related to eq. (8).

The boron content of a GaAs melt can be estimated by using the distribution coefficient for boron and the maximum boron content of a GaAs crystal. The distribution coefficient for boron was found to lie in the range between 0.3 and 0.7 by calculation from the initial boron content of a GaAs melt and the boron content of the GaAs single crystal at each solidified fraction volume. ${ }^{31)}$ Assuming that the distribution coefficient for boron in GaAs is 0.5 , the boron content of a GaAs melt was estimated to be $2 \times 10^{17}-2 \times 10^{18} \mathrm{~cm}^{-3}(0.68-6.8$ mass ppm) and $5.0 \times 10^{18}-3.8 \times 10^{19} \mathrm{~cm}^{-3}$ (17-128 mass ppm) for the LEC process with undoped and Si-doped GaAs, respectively. The boron content of a GaAs melt equilibrated with $\mathrm{B}_{2} \mathrm{O}_{3}$ flux and $\mathrm{BN}$ is compared with the estimated value using the distribution coefficient for boron in Fig. 8. The calculated values of boron and nitrogen contents using ChemSage $^{14)}$ are included in the figure. Although the calculated values are much lower than those obtained in the present work and estimated using the distribution coefficient, the trend that the boron content decreased with increasing nitrogen content agrees with the present result. The filled circle in Fig. 8 denotes the boron content of a GaAs melt

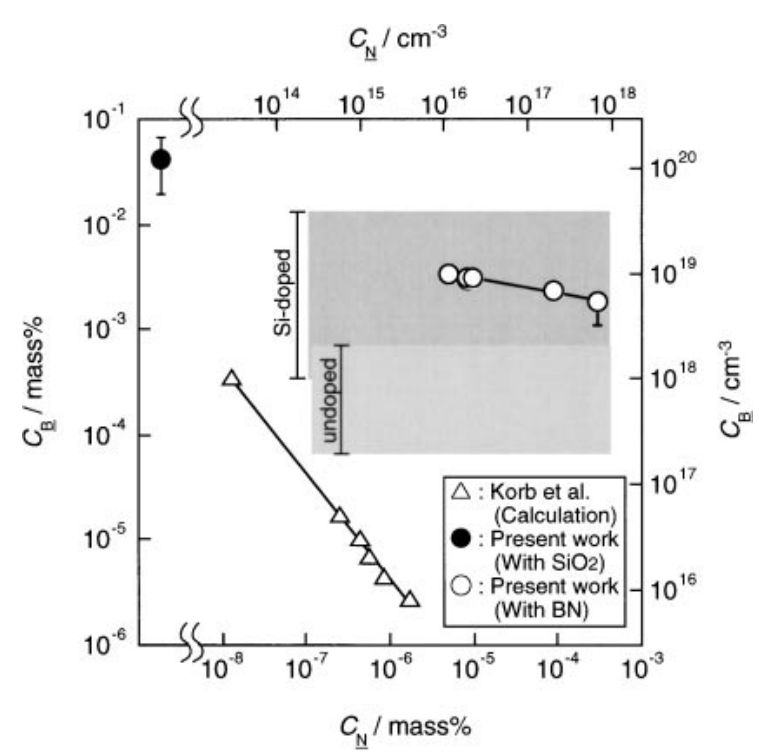

Fig. 8 Comparison of the present and the reported values of boron and nitrogen contents of a GaAs melt equilibrated with $\mathrm{B}_{2} \mathrm{O}_{3}$ flux.

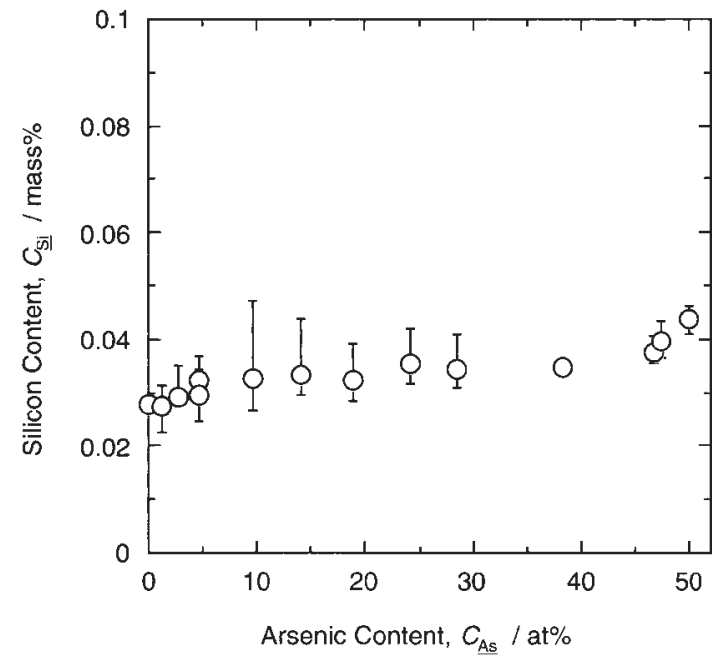

Fig. 9 Silicon content of the melt of Ga-As alloy equilibrated with $\mathrm{SiO}_{2}$ and $\mathrm{B}_{2} \mathrm{O}_{3}$ flux at $1523 \mathrm{~K}$.

coexisted with silica (see the stoichiometric composition of Ga-As alloy in Fig. 7). Since the nitrogen content of GaAs after melting with silica is expected to be very low, the plot is located on the left side in the figure. Figure 9 shows the silicon content of the melt of Ga-As alloy equilibrated with $\mathrm{B}_{2} \mathrm{O}_{3}$ flux and silica. A silicon content of around $4.6 \times$ $10^{19} \mathrm{~cm}^{-3}$ (400 mass ppm) was obtained at the stoichiometric composition of Ga-As alloy, which was much larger than that of the GaAs melt equilibrated with $\mathrm{BN}(<1$ mass ppm, $1.1 \times$ $10^{17} \mathrm{~cm}^{-3}$ ). Therefore, reaction (8) proceeded to the right and the boron content of the GaAs melt increased.

\subsection{Comparison with the contents of boron and nitrogen in the residue after crystal growth}

Since the distribution coefficients of boron and nitrogen are less than unity, boron and nitrogen in the residue after the industrial LEC crystal growth process may be close to the 


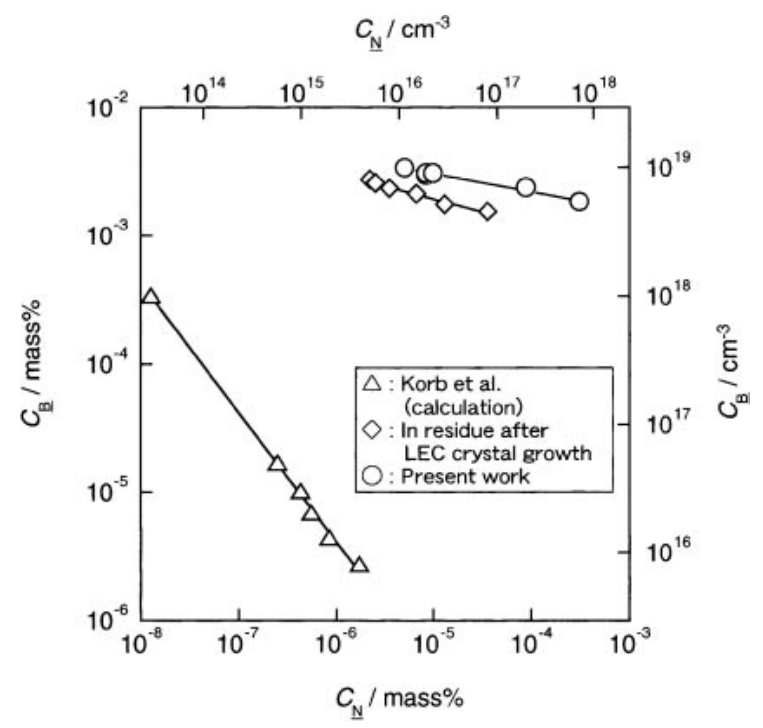

Fig. 10 Comparison of the boron and nitrogen contents of GaAs melts equilibrated with $\mathrm{B}_{2} \mathrm{O}_{3}$ flux and a $\mathrm{BN}$ crucible.

equilibrium level with BN. The boron and nitrogen contents of the residue after LEC crystal growth of GaAs were measured. Figure 10 compares the present results with those obtained from this residue analysis. In order to control the boron and nitrogen contents of the melt during the crystal growth, the $\mathrm{N}_{2}$ gas pressure in the crystal growth chamber was varied. The values of boron and nitrogen contents and the slope of the line obtained in the residue agreed well with the present laboratory data.

\section{Conclusions}

The relationship between the boron and nitrogen contents of $\mathrm{GaAs}$ and $\mathrm{InP}$ melts equilibrated with $\mathrm{B}_{2} \mathrm{O}_{3}$ flux was examined at 1523 and $1373 \mathrm{~K}$, respectively. The following results were obtained:

(1) The boron content decreased with increasing nitrogen content of the GaAs and InP melts coexisted with BN. The solubility products of $\mathrm{BN}$ in the GaAs and InP melts $\left(K_{(3)}^{\prime}=\right.$ $\left[C_{\mathrm{B}} / \operatorname{mass} \%\right] \cdot\left[C_{\underline{N}} /\right.$ mass $\left.\left.\%\right]\right)$ were expressed as follows.

GaAs: $\quad \log K_{(3)}^{\prime}=0.863 \log \left[C_{\underline{N}} /\right.$ mass $\left.\%\right]-3.21$

$$
\left(1523 \mathrm{~K}, \log \left[C_{\mathrm{N}} / \operatorname{mass} \%\right]:-5.3 \sim-3.5\right)
$$

InP: $\quad \log K_{(3)}^{\prime}=0.927 \log \left[C_{\underline{N}} /\right.$ mass $\left.\%\right]-3.50$

$$
\left(1373 \mathrm{~K}, \log \left[C_{\underline{N}} / \operatorname{mass} \%\right]:-5.0 \sim-3.6\right)
$$

(2) The boron content of a GaAs melt coexisted with silica was higher than that of one coexisted with BN. It is thought that the reduction of $\mathrm{B}_{2} \mathrm{O}_{3}$ by silicon that was introduced into the melt from silica led the increase in boron content.

(3) The relationship between boron and nitrogen contents in GaAs melts equilibrated with $\mathrm{B}_{2} \mathrm{O}_{3}$ flux and $\mathrm{BN}$ agreed well with that in the residue after the LEC crystal growth process for GaAs.

\section{Acknowledgments}

The authors thank Mr. Hisanori Koda, former graduate student at Tohoku University, for his assistance in the melt experiments. The authors are indebted to Mr. K. Tayama for his cooperation in the nitrogen analysis, and thank Mr. S. Kagaya and Mr. R. Nakamura for their continuous encouragement throughout this study.

\section{REFERENCES}

1) A. Kawasaki: Electronic Materials and Parts 34 (1995) 28-33.

2) J. Nishio and K. Terashima: J. Crystal Growth 96 (1989) 605-608.

3) J. Nishio and H. Fujita: J. Crystal Growth 134 (1993) 97-104.

4) J. D. Oberstar, B. G. Streetman, J. E. Baker, P. Williams, R. L. Henry and E. M. Awiggard: J. Crystal Growth 54 (1981) 443-448.

5) Y. Itoh, Y. Kadota, T. Nozaki, H. Fukushima and K. Takeda: Jpn. J. Appl. Phys. 28 (1989) 210-211.

6) T. Kikuta, H. Emori, T. Fukuda and K. Ishida: J. Crystal Growth 76 (1986) 517-520.

7) J. Osaka, F. Hyuga, T. Kobayashi, Y. Yamada and F. Orito: Appl. Phys. Lett. 50 (1987) 191-193.

8) H. Emori, T. Kikuta, T. Inada, T. Obokata and T. Fukuda: Jpn. J. Appl. Phys. 24 (1985) L291-L293.

9) L. Fisher, U. Lambert, G. Nagel, H. Rüfer and E. Tomzig: J. Crystal Growth 153 (1995) 90-96.

10) K. Terashima, J. Nishio, S. Washizuka and M. Watanabe: J. Crystal Growth 84 (1987) 247-252.

11) P. J. Doering, B. Freidenreich, R. J. Tobin, P. J. Pearah, J. P. Tower and R. M. Ware: Proceedings of the 6th Conference on Semi-insulating IIIV Materials, edited by A. G. Milnes and C. J. Miner, Philadelpha, PA, (1991) pp. 173-181.

12) M. Seifert, M. Neubert, W. Ulrich, B. Wiedermann, J. Donecker, J. Kluge, E. Wolf, D. Klinger and P. Rodolph: J. Crystal Growth 158 (1996) 409-417.

13) C. Gärtner, T. Flade, M. Jurisch, A. Köhler, J. Korb, U. Kretzer and B. Weinert: J. Crystal Growth 198/199 (1999) 355.

14) J. Korb, T. Flade, M. Jurisch, A. Köhler, Th. Reinhold and B. Weinert: J. Crystal Growth 198/199 (1999) 343.

15) W. A. Oates and H. Wenzl: J. Crystal Growth 191 (1998) 3033-312.

16) K. Tajima, Y. Hino, T. Narushima and Y. Iguchi: Mater. Trans., JIM 41 (2000) 714-718.

17) D. Sajuti, M. Yano, T. Narushima and Y. Iguchi: Mater. Trans., JIM 34 (1993) 1195-1199.

18) K. Wagatsuma: Metals and Technology 72 (2002) 770-776.

19) S. Itoh, H. Yamaguchi, T. Hobo and T. Kobayashi: Tetsu-to-Hagané 99 (2002) 575-579.

20) M. Saito: Bunseki Kagaku 48 (1999) 77-86.

21) Standard RSF file, VG Elemental.

22) J. Nishio and H. Fujimoto: J. Crystal Growth 141 (1994) 249-255.

23) Y. Homma and Y. Ishii: J. Appl. Phys. 56 (1984) 1892-1894.

24) C. G. Hopkins, V. R. Deline, R. J. Blattner, C. A. Evans, Jr. and T. J. Magee: Appl. Phys. Lett. 36 (1980) 989-990.

25) L. B. Ta, H. M. Hobgood and R. N. Thomas: Appl. Phys. Lett. 41 (1982) 1091-1093.

26) O. Pätzold, G. Gärtner and G. Irmer: Phys. Status Solidi B, 232 (2002) 314-322.

27) I. C. Bassignana, D. A. Macquistan, G. C. Hillier, R. Streater, D. Beckett, A. Majeed and C. Miner: J. Crystal Growth 178 (1997) 445458.

28) F. Orito, H. Okada, M. Nakajima, T. Fukuda and K. Tajimura: J. Electron. Mater. 15 (1986) 87-90.

29) G. Frigerio, C. Mucchino, J. L. Weyher, L. Zanotti and C. Paorici: J. Crystal Growth 99 (1990) 685-691.

30) K. Hashio, S. Sawada, M. Tatsumi, K. Fujita and S. Akai: J. Crystal Growth 173 (1997) 33-41.

31) T. Yamada, R. Toba and R. Nakamura: unpublished work. 